\title{
O MISMATCH SEMÂNTICO E SUAS IMPLICAÇÕES NO ENSINO DE LÍNGUA PORTUGUESA
}

\section{THE SEMANTIC MISMATCH AND ITS IMPLICATIONS IN TEACHING OF PORTUGUESE LANGUAGE}

\author{
Roza Maria Palomanes Ribeiro ${ }^{1}$ \\ Juliana Behrends de Souza ${ }^{2}$
}

Resumo: Baseando-se em estudos dentro das ciências cognitivas (Tomasello, 2003; Francis e Michaelis, 2002; Fillmore 1986), este artigo apresentará caminhos que auxiliem alunos na identificação do conflito gerador. É comum que, durante essa identificação, aconteçam mismatches, ou seja, uma falha no processo de interpretação. $\mathrm{O}$ equívoco em relação ao vocábulo conflito é recorrente, justificando a necessidade do reconhecimento do mismatch semântico. Observações feitas no ambiente escolar revelaram que professores desconhecem o assunto, gerando práticas que desconsideram o mismatch. Desta forma, apresentar-se-á uma mediação que oferece caminhos para evitá-lo. Espera-se que as contribuições desta pesquisa auxiliem professores a reconhecerem e evitarem o mismatch semântico.

Palavras-chave: Mismatch; conflito gerador; cognição.

Abstract: Based on studies within the cognitive sciences (Tomasello, 2003; Francis and Michaelis, 2002; Fillmore 1986), this article will present ways that help students identify the generating conflict. It is common that, during this identification, mismatches happen, that is, a failure in the process of interpretation. The misconception about the term conflict is recurrent, justifying the need for recognition of the semantic mismatch. Observations made in the school environment revealed that teachers do not know the subject, generating practices that disregard the mismatch. In this way, a mediation will be offered that offers ways to avoid it. It is hoped that the contributions of this research will help teachers to recognize and avoid semantic mismatch.

Keywords: Mismatch ; conflict generation ; cognition.

\section{Introdução}

\footnotetext{
${ }^{1}$ Doutora em Linguística pela Universidade Federal do Rio de Janeiro. Professora Associada de Linguística na Universidade Federal Rural do Rio de Janeiro (UFRRJ). Participa do grupo de pesquisa ELMEP. Suas pesquisas em Linguística Cognitiva centram-se no estudo das construções gramaticais e na aplicação dos pressupostos teóricos cognitivistas ao ensino de língua portuguesa. Docente do ProfLetras da UFRRJ. E-mail: rozapalomanes@terra.com.br

${ }^{2}$ Possui graduação em Português/Inglês pela Fundação Educacional Unificada Campo-grandense (2005), pósgraduação em Língua Portuguesa pelo Liceu Literário Português (2007), mestrado em Letras na UFRRJ (2018), aperfeiçoamento em Ensino de Língua Portuguesa/ Literatura CEDERJ (2012) e Tecnologia Assistiva, Projetos e Acessibilidade: Promovendo a Inclusão UNESP (2010). Atualmente, cursa doutorado em Ciências da Educação na Universidad Del Sol no Paraguai e é professora regente de Língua Portuguesa e Literatura na SME/ RJ e SEEDUC/RJ.
} 
Diversas pesquisas voltadas para o ensino buscam, em suas análises, observar, sob os mais variados vieses, teorias e recortes, as relações complexas existentes entre o professor e o aluno, entre professor e a escola, entre a escola e o aluno, entre o professor e sua formação, ou, ainda, entre qualquer um desses elementos listados e o seu meio. No entanto, o rol de pesquisas acadêmicas ainda carece de investigações acerca da relação do indivíduo com ele mesmo.

Estudos relacionados às teorias cognitivas começaram a surgir no final do século XX e ganharam força no cenário atual. Os pesquisadores passaram a demonstrar, ainda que de modo incipiente, preocupação com como são realizadas as ações educativas, já que, anteriormente, a preocupação era exclusivamente com a obtenção positiva dos resultados, desconsiderando os caminhos para sua obtenção.

As pesquisas dentro das ciências cognitivas têm se revelado fundamentais para uma análise mais profunda das questões relativas ao ensino, mais especificamente, ao ensino epilinguístico da língua portuguesa. Autores como Flavell (1979), Fillmore (1977) e Croft e Cruse (2004) passaram a fazer parte do arcabouço teórico de diversas pesquisas na busca por propostas que deem conta dos variados problemas encontrados pelos professores de língua portuguesas, sobretudo do ensino básico.

Partindo da experiência docente, foi possível perceber que alguns conteúdos ministrados em sala de aula, mais especificamente na disciplina de língua portuguesa, têm provocado equívocos de compreensão que se tornam recorrentes em diversos grupos de alunos. A utilização de vocábulos como conflito, regência, coerência e orações, por exemplo, para nomear conteúdos específicos do ensino de língua portuguesa, podem levar os alunos a conceptualizarem seus significados em seu sentido original, gerando compreensões limitadas e errôneas ao afirmarem, respectivamente, que todo conflito é uma rivalidade, a regência só está ligada aos reis, toda coerência é positiva e que as orações servem ao meio religioso.

Essa forma limitada de compreensão não seria um problema se não repercutisse negativamente, em algum momento, no ensino. Nota-se que temáticas como Romantismo, proveniente da Literatura, fazem com que os discentes conceptualizem a palavra fora de seu sentido metalinguístico, dificultando a compreensão adequada desse período literário, já que compreendem, inicialmente, que toda a obra produzida nesse período literário deve tratar, obrigatoriamente, de questões amorosas. 
O que se quer dizer é que essas palavras possuem uma carga semântica tal que, de certa forma, podem provocar problemas de interpretação e, consequentemente, a não apreensão adequada dos conteúdos ensinados, resultando em mismatches semânticos. Por mismatch semântico, entende-se que algo é colocado para análise e pode ser compreendido de modo diferente por cada um dos envolvidos, isto é, uma informação que é proferida por um emissor, recebida e processada por um indivíduo, resulta em uma decodificação diferente da esperada pelo emissor.

Especificamente para esta investigação, selecionou-se o vocábulo conflito bem como a temática referente a ele denominada Identificar o conflito gerador, presente no rol de habilidades a serem desenvolvidas e/ou aprimoradas ao longo do segundo segmento do ensino fundamental. A palavra conflito foi escolhida por apresentar-se como referência a conceitos diferentes: um conceito frequente no âmbito escolar, um que corresponde à metalinguagem do ensino da língua portuguesa e, finalmente, o sentido comum ao cotidiano do aluno.

Com base nas experiências vividas pelos professores, observadas em sala de aula, é possível afirmar que os estudantes compreendem o vocábulo conflito em seu significado isolado. Evocam um padrão de comportamento, atribuindo à palavra a especificidade semântica, conceptualizando conflito conforme sua experiência cotidiana: a palavra ativa, em suas memórias, frames de violência e enfrentamento, dificultando o trabalho da habilidade em questão. Esse equívoco, como afirmado anteriormente, é chamado, na pesquisa relatada no presente artigo, de mismatch semântico, que pode ser definido como uma falha no processo de compreensão da mensagem proferida, ou seja, quando os mapeamentos da relação forma e função são "incongruentes em relação aos padrões mais gerais da linguagem." (FRANCIS e MICHAELIS, 2003, p.2)

O objetivo geral da investigação ora relatada é evitar a ocorrência de mismatches semânticos durante o aprimoramento de habilidades relativas ao ensino de língua portuguesa na escola. Para tanto, foram selecionados os seguintes objetivos: (a) elaborar atividades que levem ao aluno a evitar os mismatches semânticos na hora da identificação do conflito gerador e (b) promover atividades que permitam ao aluno reconhecer os marcadores conjuntivos e temporais como auxiliadores dessa identificação.

Esse trabalho foi embasado nos constructos teóricos de Kleiman (2000) e Solé (1998) que detalham estratégias de antecipação de leitura e de Macedo (1991) que traz o reconhecimento dos marcadores conjuntivos e temporais sob uma visão semântica, afirmando 
que as conjunções coordenativas adversativas possuem um papel no qual as ideias contidas no primeiro plano de significação ficam semanticamente diminuídas pela conjunção adversativa, dando maior destaque à segunda ideia introduzida por esse marcador. Em relação aos advérbios e locuções temporais, destaca-se que são palavras ou expressões que modificam qualquer outra, intensificando ou acrescentando uma circunstância, formalizando o contraste semântico existente entre a introdução e o conflito gerador. Esse desequilíbrio entre papéis semânticos vai apoiar a compreensão do aluno na identificação do conflito gerador.

Como metodologia de pesquisa, apresentar-se-á uma proposta de mediação pedagógica que buscou oferecer aos educadores um caminho para sanar a dificuldade do aluno de reconhecer o conflito gerador, com a aplicação de um trabalho focado na melhoria dos seus processos cognitivos. Buscando desenvolver um trabalho de aprimoramento da habilidade Identificar do conflito gerador, no gênero conto, e evitar a ocorrência do fenômeno de mismatch foram elaboradas oito atividades direcionadas a uma única temática, já que é necessário um processo contínuo e permanente para o desenvolvimento das habilidades relacionadas aos conteúdos escolares.

\section{0 fenômeno mismatch semântico: o embasamento teórico da proposta}

Devido ao pouco referencial teórico acerca do fenômeno linguístico-cognitivo denominado mismatch ${ }^{3}$, essa seção objetiva apresentá-lo sob uma abordagem mais descritiva, ressaltando que este pode ser de natureza sintática, semântica ou ainda, sintático-semântica. Este artigo manterá seu foco na natureza puramente semântica desse fenômeno, que ainda é pouco explorada por pesquisadores cognitivistas brasileiros.

Percebe-se que os casos de mismatch são relativamente comuns nos diferentes níveis de análise linguística e acredita-se que a investigação desse tema corroborará para uma profunda compreensão dos princípios norteadores da interpretação das construções. O estudo desse fenômeno tem sido mais explorado nas pesquisas linguísticas atuais, como afirma Brodbeck (2010) ao abordar o assunto:

O fenômeno dos mismatch, ou desencontro, vem se tornando uma das pautas mais caras para discussões linguísticas recentes, especialmente, para linguistas cognitivos

\footnotetext{
${ }^{3}$ Sampaio (2013) chama esse fenômeno de desencontro. Nesta pesquisa, optou-se por utilizar o termo original mismatch, utilizado pelas autoras Francis e Michaelis (2000).
} 
que assumem programaticamente o Princípio da Continuidade na cognição humana. Essa questão é também relevante para a Gramática das Construções, porque Construção é um pareamento de forma e sentido e a hipótese default a esse respeito é a homologia da arquitetura das estruturas semânticas e formais que constituem a Construção. (BRODBECK, 2010, p. 38)

Silva (2011) apresenta uma definição de mismatch que coaduna à abordagem apresentada nesta pesquisa, afirmando que os mismatches são

desencontros que acontecem porque a construção de significados nunca se dá apartada das experiências que constituem os sujeitos, o que torna possível diferentes enquadramentos epistêmicos, em que aquilo que é posto para a visualização pode ser conceptualizado como objetos diferentes para cada um dos interactantes. (SILVA, 2011, p.16)

O fenômeno aqui analisado pode ocorrer nas relações semânticas da construção dos significados, sofrendo influência das experiências vividas pelos sujeitos, gerando diferentes enquadramentos. Aquilo que é colocado para análise pode ser compreendido de modo diferente por cada um dos envolvidos, ou seja, uma informação é proferida por um emissor, recebida e processada por um indivíduo, mas resulta em uma decodificação diferente da esperada pelo emissor.

Há entendimento movido pelo senso comum de que o processo de comunicação é contínuo e ininterrupto. Seguindo essa linha, o mismatch surge quando ocorre uma falha no processo de compreensão da mensagem proferida, ou seja, quando os mapeamentos da relação forma e função são "incongruentes em relação aos padrões mais gerais da linguagem". (FRANCIS; MICHAELIS, 2003, p. 2)

Silva (2011) utiliza a terminologia mismatch de enquadramento referencial e define esse fenômeno linguístico como "desencontros de conceptualização que podem acontecer no fluxo da comunicação entre os interlocutores, quando estes estão em uma atividade conjunta de construção de significado". (SILVA, 2011, p. 23).

As teorias cognitivas são utilizadas para dar o suporte necessário a fim de evitar situações onde haja desencontros semânticos, levando em conta que os indivíduos possuem mente situada e partilhada, auxiliando na compreensão sobre o que acontece quando o sentido é construído na mente dos envolvidos, especificamente, no modo como constroem os significados em situações concretas de comunicação.

A pesquisa aqui relatada foi motivada por uma discussão mais profunda, realizada atualmente por cognitivistas, abordando o conceito shared mind (mente partilhada), que considera que os indivíduos pensam de modo articulado a pequenos contextos sociais 
provenientes da materialização de normas, convenções e demais saberes acumulados de ordem cultural (ZLATEV et al., 2008). Zlatev et al. (2008) ainda destacam o relevante papel desempenhado pelos estudos cognitivos na área da linguagem:

While language is identical with a system of (social) norms, psychology of language is identical with the structures and processes involved in speech understanding and production as well as in the mental storage of linguistic units. (ZLATEV et al., 2008, p.300) $)^{4}$.

Percebe-se que os estudos em cognição, por muito tempo, concentraram-se na cognição individual, ou seja, os estudos da mente estavam voltados para a consciência das pessoas e em como essa mente atuava intencionalmente no mundo (MORGANTI, 2008). Correntes como essas pressupõem um sujeito não situado, resultando em uma visão essencialista de um sujeito concebido individualmente, que é o mesmo em todos os momentos (ZLATEV et al., 2008). O sujeito visto assim impossibilita a percepção de uma pessoa que pensa não só considerando suas experiências internalizadas, mas também considerando o meio que está inserido.

A ocorrência do mismatch semântico foi percebida em sala de aula, quando foi apresentada a temática do conflito gerador. Alguns estudantes partiram do vocábulo conflito, evocando um padrão interpretativo, atribuindo à palavra a especificidade de enfrentamento. Conceptualizaram a palavra conflito conforme sua experiência cotidiana: a palavra ativou, em suas memórias, as ideias de briga e discussão.

O fragmento a seguir traz um exemplo de questão em que pode ser observada a forma como o conteúdo escolar conflito gerador é comumente abordado:

Figura 1. Exemplo de questão $O$ que dizem as camisas ${ }^{5}$

\footnotetext{
4"Embora a linguagem seja equivalente a um sistema de normas (sociais), a psicologia da linguagemé equivalente às estruturas e processos envolvidos na compreensão e produção da fala, bem como no armazenamento mental de unidades linguísticas." (tradução nossa)

${ }^{5}$ Fonte: Questão retirada do PDE Plano de Desenvolvimento da Educação: SAEB. Brasília: MEC, SAEB; Inep, 2008. Disponível em: http://portal.mec.gov.br/dmdocuments/prova\%20brasil matriz2.pdf , acesso em $11 / 01 / 2017$.
} 


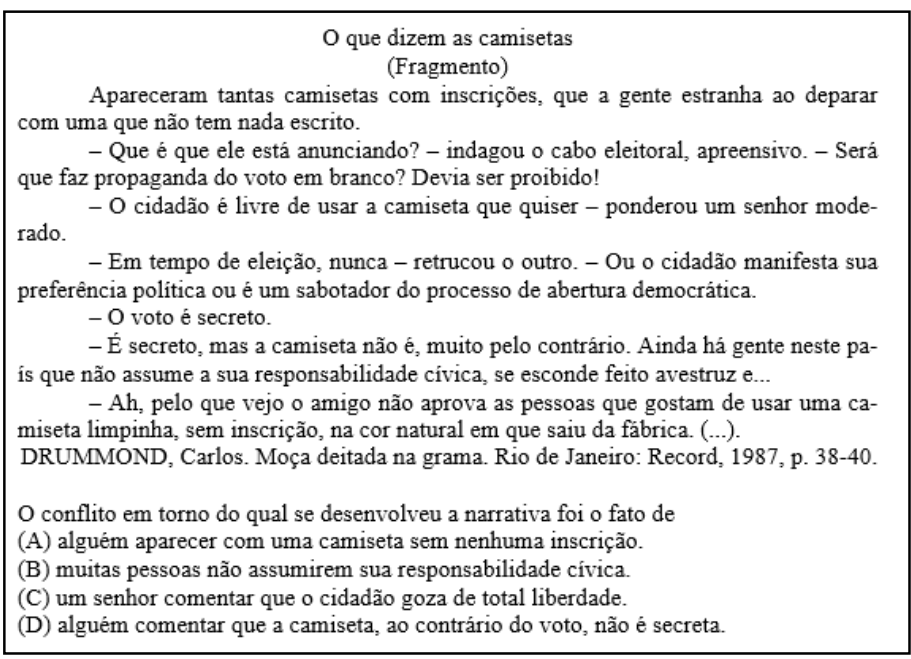

Na Figura 1, foi apresentado um item retirado do PDE (BRASIL, 2008, p. 80-82) que obteve, após a análise realizada pelo INEP, uma incidência de erro superior a 50\% nas respostas coletadas. Analisando o item com maior profundidade, percebe-se que o participante pode buscar responder o item, centrando-se no sentido isolado da palavra conflito, sem relacioná-lo aos conteúdos referentes à análise estrutural da narrativa. Sendo assim, partiria da noção de oposição, desequilíbrio, contrariedade e assinalaria a opção que mais transmite a ideia de rivalidade. Como o texto de Drummond (vide Figura 1) apresenta uma discussão acerca de um determinado assunto, o aluno tenderia a buscar os momentos de exaltação por parte dos personagens, como os trechos das falas do cabo eleitoral "- Em tempo de eleição, nunca retrucou o outro. - Ou o cidadão manifesta sua preferência política ou é um sabotador do processo de abertura democrática" e "Ainda há gente neste país que não assume a sua responsabilidade cívica, se esconde feito avestruz e...”, que se refere à ideia contida na opção B (23\% de marcação), e “-É secreto, mas a camiseta não é, muito pelo contrário”, que se refere à ideia contida na opção C ( $21 \%$ de marcação). Se todas as falas do cabo eleitoral forem analisadas, percebe-se que estas são conflituosas e opõem-se, de alguma forma, à situação inicial proposta no fragmento. $\mathrm{O}$ trecho "-O cidadão é livre de usar a camiseta que quiser", que corresponde à ideia contida na opção $\mathrm{C}$, refere-se à fala do senhor moderado e obteve somente $11 \%$ das respostas, por, provavelmente, não apresentar nenhuma oposição.

Nesse item em especial, o conflito gerador mostra-se de modo extremamente sutil no trecho "Apareceram tantas camisetas com inscrições, que a gente estranha ao deparar com uma que não tem nada escrito", exigindo do participante o conhecimento dos elementos constitutivos da narrativa para assinalar a opção A. Como o enunciado do item apresenta-se 
ambíguo e elaborado de modo incompleto, há o favorecimento da ocorrência do mismatch semântico da palavra conflito.

Com base no exposto, pode-se perceber uma possível ocorrência do fenômeno mismatch semântico na interpretação do enunciado da questão. O documento PDE informa que a opção correspondente ao gabarito, a opção A, obteve $44 \%$ das respostas, quanto as opções B e D, consideradas erradas e que podem indicar uma situação de interpretação com a influência do fenômeno mismatch, juntas, somaram, também, 44\%. Nota-se o quão importante é a percepção desse fenômeno e suas implicações negativas no ensino. Na obra, de onde fora retirada a questão acima exposta, não há nenhuma orientação ao professor, com vistas a evitar o problema e direcionar o aluno à opção correta.

Fica claro, também, que a aplicação desse descritor na avaliação que foi proposta aos alunos, revelou que foi obtido um percentual inferior a 50\% dos acertos esperados para a opção A, revelando a complexidade da compreensão do tema. Os alunos que marcaram as demais opções $(55 \%)$ podem não ter entendido a solicitação do enunciado ou ainda não terem compreendido que a habilidade de identificar o conflito gerador do enredo faz parte do esquema de constituição e organização de uma narrativa. A não observância dos reais motivos para o erro cometido pelos alunos pode favorecer o não aprimoramento linguístico, já que, se não fica claro o motivo, não há preocupação em solucionar o problema de modo definitivo, sustentando premissas de que os alunos não estudam porque não querem ou que erram por que não querem aprender.

Para evitar a ocorrência desse fenômeno, bastava a elaboração de enunciados mais coerentes, situados e que ativassem frames que não induzissem o participante ao erro naquela base conceptual, uma vez que, como afirma Fillmore (1982), o significado das palavras é subordinado a frames. Poder-se-ia utilizar como defesa à elaboração do item, o fato de que a maioria acertou. Entretanto, se analisarmos sob a ótica de que as opções B e D constituem uma mesma ideia e poderiam estar juntas na mesma opção, o total de marcação das duas, 44\%, equivalem ao total obtido na opção A.

A ocorrência de mismatches semânticos pode não ser considerada um problema e passar despercebida. Todavia, situações assim são comuns em sala de aula, especialmente no ensino de metalinguagem, nas quais a sua ocorrência também pode causar o não aprendizado de determinados conceitos relevantes para futuras análises linguísticas.

\section{Caminhos metodológicos: proposição de mediação pedagógica}


A elaboração de uma forma prática para identificação do conflito no gênero textual conto seguiu as linhas de estudo de Gancho (2002), Garcia (2010) e Moisés (2006), partindo da identificação de palavras que marcam, justamente, o desequilíbrio causado pelo conflito gerador. Após a leitura de diversos contos escritos por diversos autores, percebeu-se que há a tendência em marcar o início do conflito com uma expressão temporal ou uma conjunção de valor adversativo. A carga semântica presente nas expressões de repente, entretanto, mas, quando, entre outras, auxilia a produção da complicação e a sua inserção ao longo da narrativa.

A elaboração da aplicação da proposta de mediação pedagógica que, aqui, se relata, tem como escopo específico a identificação do conflito com o uso das expressões em itálico no parágrafo anterior. Esta pesquisa partiu do interesse de se propor alternativas que facilitem o trabalho do professor no desenvolvimento da habilidade de identificar o conflito gerador, evitando a ocorrência do fenômeno mismatch semântico, já definido na seção anterior com auxílio de exemplos e referencial teórico diverso.

Como primeira atividade, propôs-se a aplicação de uma avaliação diagnóstica para identificar o que os estudantes já sabiam e os conhecimentos que ainda não dominavam em termos de estrutura da narrativa a fim de elaborar atividades compatíveis a sua capacidade de reflexão. Entendemos, com Morais (2007), que “...ensinar é fornecer uma ajuda ajustada aos aprendizes, para que eles (re)construam seu saber" (MORAIS, 2007, p. 46). Uma breve explicação sobre os elementos da narrativa foi realizada com destaque para a apresentação do conceito de conflito gerador e cada aluno recebeu uma folha com o conto A lição da caveira ${ }^{6}$, que foi escolhido por ser indicado para a faixa etária dos alunos.

Após a leitura individual do texto, os alunos foram orientados a assinalar o trecho que indica o conflito gerador do conto.

Figura 2. Exemplo de questão ${ }^{7}$

\footnotetext{
${ }^{6}$ INSTITUTO AYRTON SENNA. Fórmula da Vitória. São Paulo: Global Editora, 2011.

${ }^{7}$ Elaborado para esta pesquisa.
} 


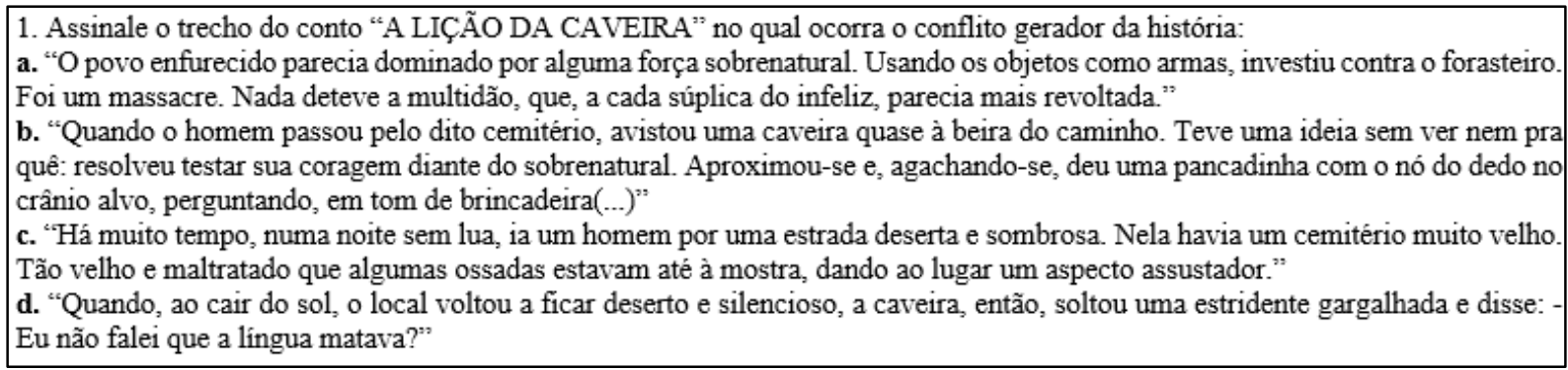

Importante destacar que no conto, especificamente anterior ao desfecho, há um momento de extrema tensão e conflito com grande rivalidade entre os personagens. $\mathrm{O}$ esperado era que os resultados demonstrassem uma maior tendência a assinalar o clímax em vez do conflito, por este possuir mais rivalidade que aquele.

Quadro 1. Resumo da atividade 1

\begin{tabular}{|l|l|l|}
\hline \multirow{4}{*}{ Atividade 1 } & \multicolumn{2}{|c|}{ Atividade diagnóstica } \\
\cline { 2 - 3 } & Objetivos & Identificar as dificuldades específicas na assimilação do conteúdo. \\
\cline { 2 - 3 } & Atividade & $\begin{array}{l}\text { Leitura individual; } \\
\text { Resolução questão. }\end{array}$ \\
\cline { 2 - 3 } & Material & Folhas xerografadas. \\
\cline { 2 - 3 } & Duração & 2 horas-aula \\
\hline
\end{tabular}

A partir da segunda atividade, propôs-se a seleção de uma grande temática que nortearia as atividades posteriores. Como sugestão, trabalhou-se com textos relacionados à mulher, que objetivavam promover o debate e reflexão sobre o quão dificultosas podem ser as relações sociais em torno das mulheres. Essa temática foi escolhida por apresentar diversos exemplos de conflitos e, teoricamente, deveria provocar um maior envolvimento dos alunos à proposta apresentada.

Nessa etapa da mediação pedagógica intitulada Apresentação da temática Mulher por excelência e coleta das primeiras impressões dos alunos informou-se aos estudantes que seu objetivo seria conhecer e compreender a proposta de trabalho, despertando, com isso, sua curiosidade pelo tema. Entendemos ser tal apresentação uma etapa importante, pois busca verificar o conhecimento prévio do aluno em relação ao assunto e, ainda, descortinar as expectativas relacionadas ao tema. Apesar de não terem a materialidade do texto, os debates seguiram, de modo adaptado, o método de antecipação proposto por Solé (1998) que valoriza a verificação do conhecimento prévio antes da proposição de qualquer atividade que envolva linguagem. Nesse momento, pôde ser construída coletivamente uma nuvem de palavras ${ }^{8}$, no

\footnotetext{
${ }^{8}$ Uma nuvem de palavras é um recurso gráfico (usado principalmente na internet) para descrever os termos mais frequentes de um determinado texto/assunto. $\mathrm{O}$ tamanho da fonte em que a palavra é apresentada é uma função da
} 
quadro branco com a utilização dos vocábulos fornecidos pelos alunos e, imediatamente após, o professor-pesquisador propôs o seguinte questionamento: Qual a importância da mulher na sociedade? Os alunos foram orientados a darem a sua opinião com base nas discussões realizadas em sala e nas suas próprias percepções pessoais. Para alcançar o objetivo específico dessa tarefa, verificou-se a relevância do tema para o grupo analisado.

Quadro 2. Resumo da atividade 2

\begin{tabular}{|l|l|l|}
\hline \multirow{4}{*}{} & \multicolumn{2}{|c|}{ Apresentação da temática e coleta das primeiras impressões dos alunos. } \\
\cline { 2 - 3 } & Objetivos & $\begin{array}{l}\text { Conhecer e compreender a proposta de trabalho; } \\
\text { Despertar a curiosidade pelo tema. }\end{array}$ \\
\cline { 2 - 3 } & Atividade & $\begin{array}{l}\text { Debate com a turma; } \\
\text { Produção coletiva de nuvem de palavras; } \\
\text { Produção textual individual. }\end{array}$ \\
\cline { 2 - 3 } & Material & Folhas xerografadas. \\
\cline { 2 - 3 } & Duração & 3 horas-aula \\
\hline
\end{tabular}

A terceira atividade teve por objetivo coletar as impressões dos alunos acerca do campo semântico da palavra conflito e ampliar seu vocabulário. O campo semântico, à guisa de informação, é formado pelas possibilidades de significação que uma mesma palavra pode assumir, dependendo de como for empregada e o contexto em que estará inserida. Para tanto, foram entregues folhas xerografadas, nas quais os alunos deveriam inserir livremente as palavras que lhes viessem à mente. Os elementos da narrativa já haviam sido apresentados em aulas anteriores e esperava-se que ocorressem associações ao elemento estruturador do conto, o conflito.

Durante a aplicação da avaliação diagnóstica, ficou claro que o vocábulo conflito poderia evocar uma interpretação não esperada, induzindo aos indivíduos a erros de compreensão. Para verificar quais palavras estavam associadas ao vocábulo analisado, os alunos tiveram que preencher uma folha xerografada com quatro palavras que tivessem o significado próximo a palavra conflito. Orientou-se pela não utilização da palavra sinônimo, pois, como afirma Tamba (2006) e Cançado (2015), não existem sinônimos perfeitos.

A seleção de unidades lexicais específicas e suas relações com o contexto possibilitam a compreensão, a descrição e a explicação da visão de mundo (ideologia, valores, práticas socioculturais) de agrupamentos humanos, ou seja, um grupo sócio-linguístico-cultural. (ARAGÃO, 2000, p. 54 apud MOURA, 2008, p. 555) Cabe, ainda, ressaltar que é no léxico

frequência da palavra no texto: palavras mais frequentes são desenhadas em fontes de tamanho maior, palavras menos frequentes são desenhadas em fontes de tamanho menor. (Disponível em http://www.uff.br/cdme/lpp/lpp-

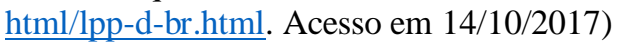


que a linguagem é atualizada e ocorrem as adequações às novas necessidades. Esse processo de ampliação lexical é dinâmico e constante, já que o léxico é o único domínio da língua que constitui um sistema aberto. (BIDERMAN, 2001)

As atividades 2 e 3 possibilitaram a conscientização dos alunos acerca do tema e estimularam a abertura para o novo. Essas etapas foram importantes, já que os alunos são os sujeitos da aprendizagem e devem necessariamente estar envolvidos com a proposta.

Quadro 3. Resumo da atividade 3

\begin{tabular}{|l|l|l|}
\hline \multirow{2}{*}{} & \multicolumn{2}{|c|}{ Definição da palavra conflito. } \\
\cline { 2 - 3 } & Objetivos & $\begin{array}{l}\text { Coletar as impressões dos alunos acerca do campo semântico da } \\
\text { palavra conflito; } \\
\text { Ampliar o vocabulário dos alunos. }\end{array}$ \\
\cline { 2 - 3 } Atividade 2 & Atividades & $\begin{array}{l}\text { Esclarecimento de dúvidas quanto ao vocabulário; } \\
\text { Preenchimento de ficha de trabalho. }\end{array}$ \\
\cline { 2 - 3 } & Material & Folhas xerografadas. \\
\cline { 2 - 3 } & Duração & 2 horas-aula \\
\hline
\end{tabular}

A quarta atividade demandou maior complexidade se comparada às anteriores, tendo como objetivos apresentar o gênero notícia e o elemento narrativo desfecho; construir o conflito a partir de um desfecho apresentado e reconhecer o conflito como o elemento estruturador de uma narrativa. Foram propostas atividades específicas para alcançar os objetivos listados, tais como a leitura oral da notícia, esclarecimento de dúvidas quanto ao vocabulário, interpretação das informações apresentadas com explanação oral, produção escrita de um possível conflito gerador para aquele desfecho e a reescrita do texto produzido.

Figura 3. Exemplo de notícia ${ }^{9}$

\footnotetext{
${ }^{9}$ Disponível em: http://g1.globo.com/minas-gerais/noticia/2016/08/mulher-morre-esfaqueada-em-belohorizonte-ex-e-suspeito.html. Acesso em 01/05/2018.
} 


12/08/2016 17h34 - Atualizado em 12/08/2016 17h34
Horlzonte; eX é SUSPelito
De acordo com a PM, outras duas pessoas também foram feridas.
Após o crime, homem conseguiu fugir.
Do G1 mo
Uma mulher, de 32 anos, morreu, na tarde desta sexta-feira (12), após ser esfaqueada na
Região Noroeste de Belo Horizonte. De acordo com a Polícia Militar (PM), o ex-companheiro é o
suspeito do crime.
Segundo a corporação, o homem invadiu a casa da vítima, localizada no bairro Santo André.
Além da mulher, uma idosa, de 72 anos, e um adolescente, de 16, foram feridos por golpes de
faca.
De acordo com a PM, o Serviço de Atendimento Móvel de Urgência (Samu) foi acionado. A
equipe de resgate tentou reanimar a mulher, mas ela não resistiu e morreu no local. A idosa e o
jovem foram socorridos e levados para o Hospital de Pronto-Socorro João XXIII.
Após o crime, o homem conseguiu fugir.

A notícia apresentada na figura 3 não revela todos os fatos culminantes e interessantes, favorecendo o pensamento criativo para a construção do conflito. A notícia foi lida para a turma e problematizada em um debate acerca dos direitos humanos. Após esse debate, foi proposto que cada aluno pensasse em um possível conflito para o desfecho apresentado na notícia e escrevesse em uma folha utilizada para essa finalidade.

A atividade 4 contribuiu para a identificação do conflito gerador, fixando e esclarecendo qual o conteúdo deveria estar presente nesse momento da narrativa. Com o objetivo de aprimorar a habilidade de identificação, foram propostas mais atividades que serão descritas na sequência.

Quadro 4. Resumo da atividade 4

\begin{tabular}{|l|l|l|}
\hline \multirow{4}{*}{} & \multicolumn{2}{|c|}{ Construção de possíveis conflitos geradores para o desfecho apresentado na notícia } \\
\cline { 2 - 3 } & Objetivos & $\begin{array}{l}\text { Apresentar o gênero notícia; } \\
\text { Apresentar o elemento narrativo desfecho; } \\
\text { Construir o conflito a partir de um desfecho apresentado; } \\
\text { Reconhecer o conflito como o elemento estruturador de uma narrativa. }\end{array}$ \\
\cline { 2 - 3 } & Atividades & $\begin{array}{l}\text { Leitura oral da notícia; } \\
\text { Interpretação das informações apresentadas com explanação oral; } \\
\text { Produção escrita de um possível conflito gerador para aquele desfecho. }\end{array}$ \\
\cline { 2 - 3 } & Material & Folhas xerografadas; \\
\cline { 2 - 3 } & Duração & 4 horas-aula \\
\hline
\end{tabular}

A quinta atividade apoiou-se em nas estratégias de leitura propostas por Kleiman (2000) e Solé (1998) para garantir o aprimoramento da habilidade de identificação o conflito gerador. 
Os objetivos traçados para esta etapa buscavam levar os alunos a conhecer o gênero textual conto, suas partes constitutivas e aplicar estratégias de leitura. Para tanto, foi realizada a leitura oral do conto A moça tecelã, com aula expositiva sobre os elementos constitutivos do conto: introdução, conflito gerador, clímax e desfecho, anotação dessas informações no caderno e explicação oral das partes do texto.

Antes da descrição dessa atividade, faz-se necessário um maior aprofundamento das estratégias de pré-leitura descritas por Kleiman (2000) e Solé (1998). Essas estratégias objetivam despertar o interesse do aluno por meio de atividades de antecipação da leitura com a análise da capa, título, subtítulo, sinopse, verificação do conhecimento prévio sobre o assunto e ainda expectativas relacionadas ao suporte, à formatação do gênero, ao autor ou instituição responsável pela publicação. Solé (1998) destaca a importância desse trabalho de antecipação afirmando que:

[...] atividades em que os alunos tenham que perguntar, prever, recapitular para os colegas, opinar, resumir, comparar suas opiniões com relação ao que leram, tudo isso fomenta uma leitura inteligente e crítica, na qual o leitor vê a si mesmo como protagonista do processo de construção de significados. (SOLÉ, 1998, p. 173)

Acerca da relevância das vivências e dos conhecimentos prévios do leitor, Kleiman(1989) afirma que repertório de experiências permite ao leitor fazer previsões e inferências sobre o texto, embasando-se em sua experiência sociocultural e em seu conhecimento de mundo. Essa atmosfera gerada no contato entre textos, pessoas e ideologias resulta no real significado da leitura que pode definir-se como espaço de manifestação da própria linguagem. A antecipação também é considerada pela autora citada como uma das estratégias para garantir a compreensão do texto e a relaciona uma estratégia cognitiva que se baseia em diversos elementos textuais. A autora ainda valoriza os elementos paratextuais ao afirmar que

[...] leitura implica uma atividade de procura pelo leitor, no seu passado de lembranças e conhecimentos, daqueles que são relevantes à compreensão de um texto, que fornece pistas e sugere caminhos, mas que certamente não explicita tudo o que seria possível explicitar. (KLEIMAN, 1989, p. 27)

No trabalho desenvolvido na atividade 5 com o conto A moça tecelã, optou-se por seguir um roteiro de cinco perguntas referentes aos aspectos a serem trabalhados. A primeira questão contemplava a observação e resgate dos elementos gráficos presentes na capa. 


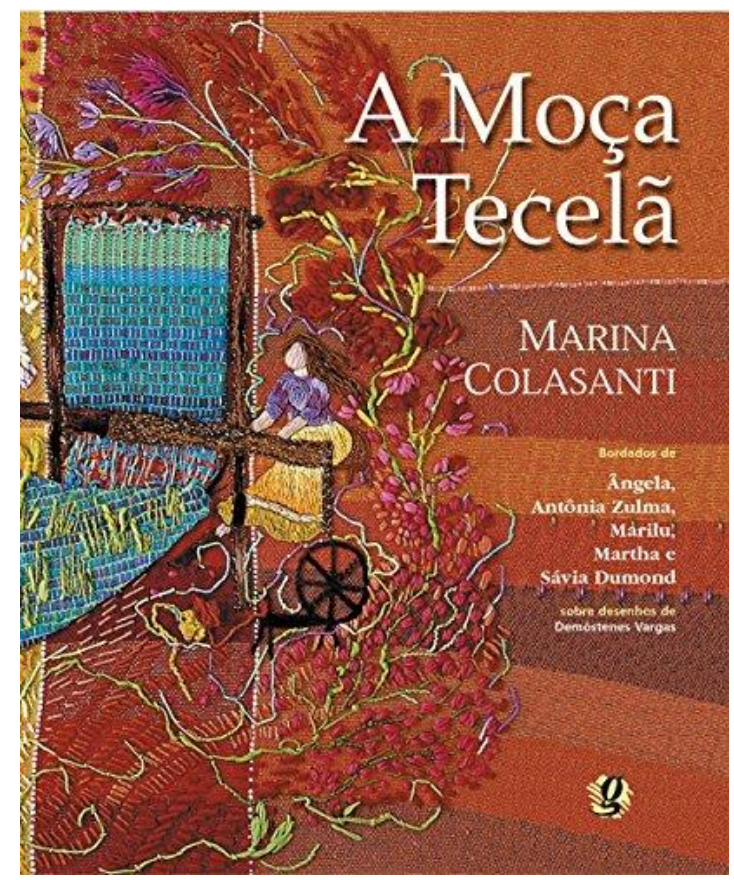

Após a leitura das imagens da capa, foi apresentada a segunda questão que objetivava a observação da relação entre as imagens e o título: A imagem da menina/mulher cercada de linhas e bordados possui qual relação com o título? Acredita-se que a utilização de conhecimentos prévios e das associações imagéticas presentes na capa despertam o interesse dos alunos pela leitura.

$\mathrm{Na}$ terceira questão, Ao folhearmos o livro, observamos páginas muito coloridas $e$ parecidas entre si. Esses elementos nos remetem a que atividade? a etapa de antecipação da leitura foi fundamental para a ampliação do vocabulário e contribuiu para a compreensão da totalidade do conto. Com a quarta questão, os alunos foram conduzidos a levantar hipóteses sobre o texto. Foi-lhes perguntado se é possível se ter alguma ideia do que é tratado no conto, com base, apenas, no título e nas imagens. Compreende-se que o levantamento de hipóteses, além de motivar o leitor, resgata questões pertinentes ao cotidiano deles.

A última questão contempla a leitura da sinopse do livro presente na contracapa e as impressões primárias do leitor sobre o livro, após lê-las e ter analisado os já referidos aspectos da obra.

Figura 5. Contracapa do livro A moça tecelã 


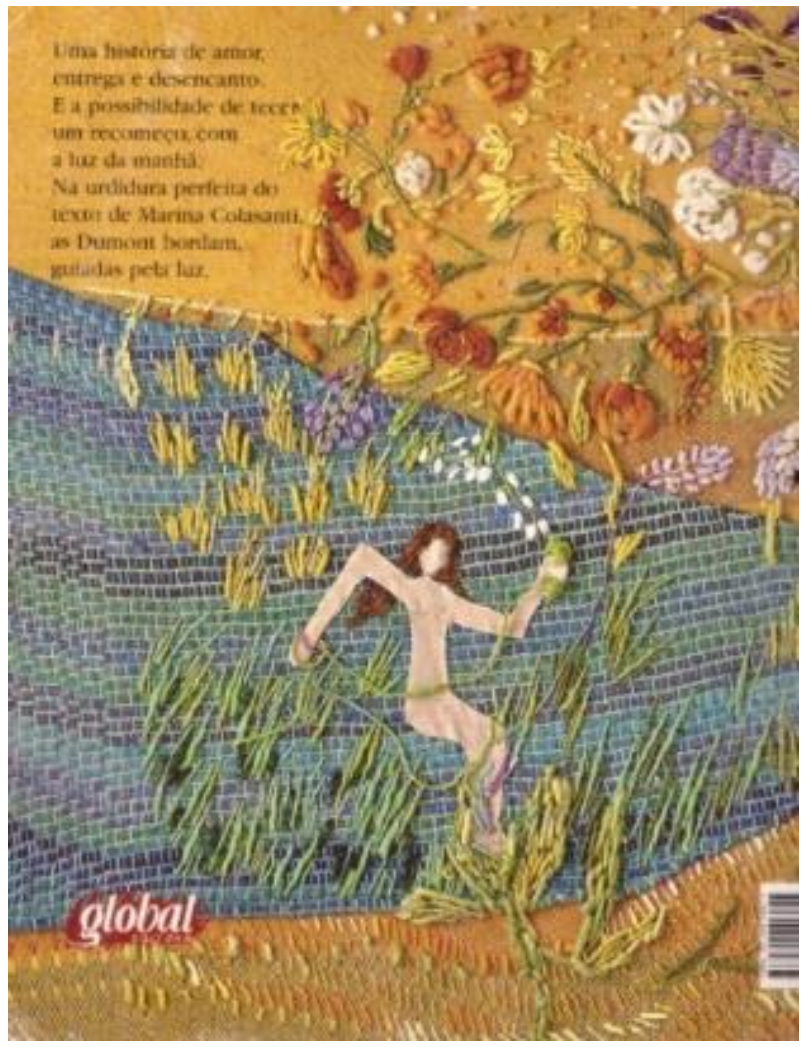

A antecipação da leitura foi essencial no trabalho de mediação, pois o professor, diante a roteirização e o planejamento adequado ao perfil do aluno, assumiu seu papel de mediador e propiciou novas experiências de leitura.

Em seguida, foi feita a leitura do conto, acompanhada por um momento para a pós-leitura, com atividades de interpretação sobre o texto em grupo e individual. Percebeu-se que as estratégias de antecipação de leitura descritas por Kleiman (2000) e Solé (1998) facilitaram a compreensão das partes constitutivas do conto apresentado. Quando os leitores compreendem profundamente a narrativa, há maior facilidade na identificação do conflito gerador e consequentemente das outras partes do conto, sendo assim, observa-se que, após se trabalhar a interpretação do texto, os conhecimentos acerca da estrutura da narrativa são compreendidos com mais facilidade.

Quadro 5. Resumo da atividade 5

\begin{tabular}{|l|l|l|}
\hline \multirow{4}{*}{ Atividade 5 } & \multicolumn{2}{|c|}{ Leitura do conto A moça tecelã. } \\
\cline { 2 - 3 } & Objetivos & $\begin{array}{l}\text { Conhecer o gênero textual conto; } \\
\text { Reconhecer as partes da narrativa; } \\
\text { Aplicar estratégias de leitura. }\end{array}$ \\
\cline { 2 - 3 } & Atividades & $\begin{array}{l}\text { Leitura oral do conto; } \\
\text { Aula expositiva sobre os elementos constitutivos do conto. }\end{array}$ \\
\cline { 2 - 3 } & Material & Folha com o conto impresso $($ A moça tecelã $) ;$ \\
\cline { 2 - 3 } & Duração & 2 horas-aula \\
\hline
\end{tabular}


A sexta atividade foi realizada após a interpretação do conto $A$ moça tecelã e a aplicação das estratégias de antecipação da leitura (KLEIMAN, 2000; SOLÉ, 1998), solicitando aos alunos a produção de um texto, que contenha a reescrita do conflito gerador.

Para que os alunos tivessem o arcabouço vocabular necessário para a construção dos textos, sugeriu-se a aplicação da atividade 6 que visava fomentar nova escolhas lexicais e suas implicações semânticas. As folhas xerografadas utilizadas na atividade anterior foram entregues novamente aos alunos, que foram orientados a relerem o texto, agora individualmente, e sublinharem o trecho do conflito gerador.

Após a identificação da parte do texto solicitada, foi entregue aos alunos uma folha para a reescrita do conflito gerador. O objetivo dessa atividade foi garantir o aprimoramento na identificação da parte da narrativa em questão e fazê-los se sentirem familiarizados com o tom utilizado pelos autores para marcar esse momento de desequilíbrio da narrativa.

Os alunos que não marcarem corretamente o conflito na folha xerografada com o texto de Colasanti, foram orientados a refazerem a leitura e procurarem, de forma mais atenciosa, o conflito gerador. Somente após esse exercício metacognitivo é que foi dado início à reescrita, que buscava, também, identificar como e onde os textos poderiam ser modificados. Araújo (2004) ressalta que

[...] atividades de revisão e reescrita de textos implicam não apenas no saber linguístico e textual do aluno, a ampliação de seu repertório e recursos expressivos, mas também o saber - fazer, a ampliação de seus conhecimentos de composição de texto". (ARAÚJO, 2004, p. 96).

O trecho do conto de Colasanti que indica o conflito gerador pode ser observado na passagem "Mas tecendo e tecendo, ela própria trouxe o tempo em que se sentiu sozinha, e pela primeira vez pensou em como seria bom ter um marido ao lado.” (COLASANTI, 2004, p. 4). Percebe-se que o conflito inicia com o marcador adversativo mas, sendo esta uma prática muito comum entre os contistas no estabelecimento do conflito.

Percebeu-se que autores como Cora Coralina no conto O lampião da Rua do Fogo, com o trecho "Então, se misturava vinho, conhaque e aniseta; só voltava para casa carregado pelos companheiros, que o entregavam aos cuidados da mulher"; Ruth Rocha no conto Rubens, $o$ semeador, com o trecho "Mas um dia, minha mãe escolheu um caminho diferente para levar à escola"; Ana Maria Machado no conto A menina que vivia perdendo, no trecho "Mas o que Lena perdia era muito sério" e Rubem Fonseca no conto O outro, com o trecho "Mas sempre 
tinha a impressão de que não havia feito nada de útil”, costumam, assim como Colasanti, iniciar o conflito com um marcador temporal ou adversativo.

A reescrita faz parte do processo de escrita, sendo esta uma prática trabalhosa, mas essencial para o ensino da produção textual, e nesse caso, é utilizada para auxiliar na compreensão das partes do enredo. Pode-se afirmar que escrever é um exercício que só se aprimora com prática constante atrelada indissociavelmente à prática da leitura. Ler o texto e depois reescrevê-lo colabora decisivamente para a sensibilidade frente às adaptações cabíveis, já que é pela leitura que os alunos assimilam as estruturas próprias da língua escrita e do conflito gerador.

Como já dito anteriormente nesta seção, a aplicação da atividade de reescrita busca garantir o aprimoramento na identificação do conflito gerador e fazendo os alunos sentirem-se familiarizados com o tom utilizado pela autora para assinalar o momento de desequilíbrio da narrativa. Apesar de a habilidade a ser aprimorada durante a aplicação das atividades desta mediação ser relacionada diretamente à leitura, há a necessidade de apoiar esse aprimoramento em uma produção escrita. Nota-se que os alunos pertencentes à faixa etária do segundo segmento do Ensino Fundamental ainda necessitam da materialidade e a concretude da escrita para apoiarem sua aprendizagem. Garcez (2016) postula que é importante transmitir conhecimentos por meio da escrita, já que na comunicação oral os indivíduos apoiam-se no contexto e na comunicação escrita, devendo-se sempre seguir certas especificidades e exigências.

[...] Tratamos de forma diferente a sintaxe, o vocabulário e a própria organização do discurso. É pela convivência com textos escritos de diversos gêneros que vamos incorporando às nossas habilidades um efetivo conhecimento da escrita. (GARCEZ, 2001, p. 6-7)

De acordo com a autora, escrever é uma habilidade que pode ser desenvolvida e não um dom que poucas pessoas têm, sendo este um ato que exige empenho e trabalho e não um fenômeno espontâneo. A atenção e o tempo dispensado à produção textual são fundamentais, visto que os indivíduos vivem e convivem fazendo uso de textos orais e escritos. Garantir a ampliação dessa competência linguística é também assegurar o exercício da cidadania.

Quadro 6. Resumo da atividade 6

\begin{tabular}{|l|l|l|}
\hline \multirow{2}{*}{ Objetivos } & Produção de conflito gerador do conto A moça tecelã. \\
\cline { 2 - 3 } & & $\begin{array}{l}\text { Identificar os elementos da narrativa; } \\
\text { Reconhecer o conflito gerador como elemento estruturador do conto; } \\
\text { Reelaborar o conflito apresentado no conto A moça tecelã. }\end{array}$ \\
\hline
\end{tabular}




\begin{tabular}{|l|l|l|}
\hline \multirow{3}{*}{ Atividade 6 } & Atividades & $\begin{array}{l}\text { Releitura individual do conto; } \\
\text { Identificação do conflito gerador; } \\
\text { Produção textual: reescrevendo o conflito do conto A moça tecelãa. }\end{array}$ \\
\cline { 2 - 3 } & Material & $\begin{array}{l}\text { Folha com o conto impresso }(\text { A moça tecela }) ; \\
\text { Folha xerografada para a produção textual; }\end{array}$ \\
\cline { 2 - 3 } & Duração & 3 horas-aula \\
\hline
\end{tabular}

A sétima atividade pautou-se na necessidade de o aluno reconhecer e compreender a funcionalidade das conjunções e marcadores temporais e sua importância na estruturação do conto. Para tal, foram aplicadas atividades voltadas à apresentação das conjunções e marcadores temporais, por meio de quadros expositivos das adversativas e dos advérbios e locuções adverbiais comumente utilizados no início do conflito gerador.

Propôs-se, também, leitura coletiva dos contos Onde os oceanos se encontram ${ }^{10}$ (marcador temporal) e Rosto atrás do rosto ${ }^{11}$ (conjunção adversativa), ambos de Marina Colasanti. Após a leitura, foi feita uma análise das personagens femininas e a identificação dos conflitos geradores a partir dos marcadores conjuntivos e temporais. Para finalizar, propõs-se a realização de exercícios com conjunções e marcadores temporais. Elegeram-se, somente, as conjunções adversativas mas, porém, contudo, todavia e entretanto, pois são as mais utilizadas ou que costumam aparecer introduzindo um conflito gerador. Deixou-se claro aos alunos que tais palavras possuem uma carga significativa que remete a uma oposição de ideias, utilizando exemplos colhidos da obra de Macedo (1991).

Estudei muito (+), [mas] não aprendi.(-)

Fiz o possível e impossível (+), [mas] nada consegui. (-)

O dia está lindo (+), [mas] não vou sair de casa. (-)

Foram apresentados, aos alunos, outros exemplos confrontantes aos anteriores, para que possam realmente perceber o desequilíbrio causado pela conjunção adversativa nas frases.

Não presto (-), [mas] eu te amo. (+)

Realmente ela matou (-), [mas] foi por amor. (+)

Estudei muito (-), [mas] aprendi tudo. (+)

Os símbolos (+) e (-) indicam, respectivamente, sentido positivo e sentido negativo de seu conteúdo semântico. Macedo (1991) afirma que ao contrastar (+) e (-) percebe-se a

\footnotetext{
${ }^{10}$ COLASANTI, Marina. Mais de 100 histórias maravilhosas. São Paulo: Global, 2015.

${ }^{11}$ COLASANTI, Marina. Mais de 100 histórias maravilhosas. São Paulo: Global, 2015.
} 
impossibilidade de obter-se uma soma, como no caso do uso das aditivas, inferindo-se que a conjunção adversativa é a conjunção da subtração, ou como costumeiramente se usa, a conjunção da oposição.

Nessa posição putativa do falante é que vai ocorrer a opção entre um $e$ e um mas. Na sua cosmovisão, o falante vai colocando na frase o seu sentimento do mundo, achando tais coisas como positivas e outras como negativas. É claro que algumas há unanimidade coletiva. (MACEDO, 1991, p. 309)

Os alunos devem compreender o papel desempenhado pelas conjunções adversativas na alteração na progressão do enredo. A partir daqui, pode ser iniciada a explicação com a definição de advérbio de Macedo (1991) que propõe que os advérbios são palavras que modificam qualquer outra, intensificando ou acrescentando uma circunstância. Deve-se focar na função modificadora do advérbio, comparando-o com o contraste semântico existente entre a introdução e o conflito gerador das narrativas estudadas até ali.

Concluída esta etapa, foram entregues aos alunos folhas xerografas com os textos do conto Onde os oceanos se encontram. Cabe ressaltar que foram realizadas, novamente, as estratégias de mediação da leitura seguindo os constructos de Solé (1998) e Kleiman (2000), sendo questionado o título do conto, levantando hipóteses sobre o assunto que seria abordado; quem seriam os personagens e qual espaço aconteceria a narrativa. Os alunos, a exemplo da atividade 6, já devem conhecer as expectativas para as respostas, posicionando-se conforme o questionamento que foi levantado e proporcionando diferentes pontos será entregue uma questão de múltipla escolha para que os alunos localizem o conflito gerador.

Figura 6. Exemplo de questão ${ }^{12}$

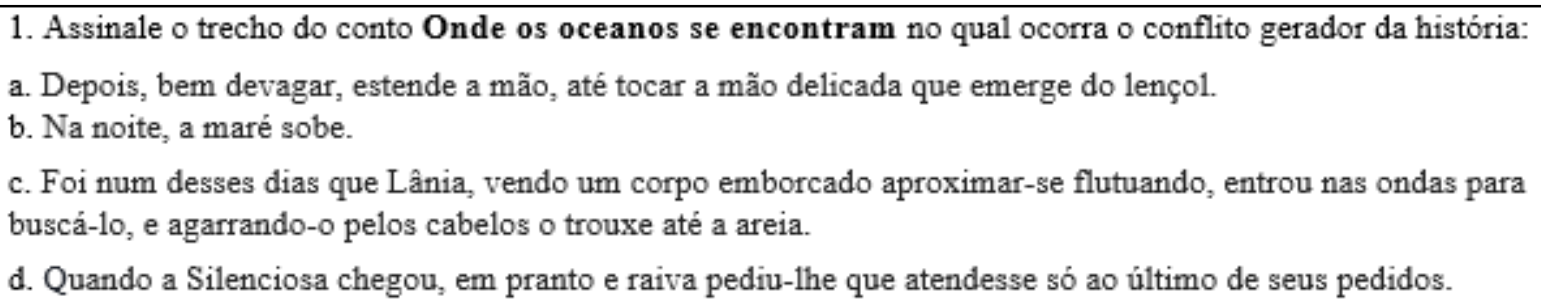

Lidas as opções, os alunos puderam perceber que todas as respostas iniciam com um advérbio, uma locução ou uma expressão que remetia a alguma ideia de tempo. Tal seleção foi intencional, para que eles começassem a treinar a identificação do conflito por meio do conteúdo e não só pelos marcadores.

\footnotetext{
${ }^{12}$ Elaborado para esta pesquisa.
} 
Em outro momento, realizou-se uma pequena revisão dos marcadores adversativos e temporais, sendo entregues aos alunos novas folhas xerografadas, agora com o texto Rosto atrás do rosto. Novamente, foram aplicadas as estratégias de antecipação da leitura e realizada uma leitura coletiva do conto.

Figura 7. Exemplo de questão ${ }^{13}$

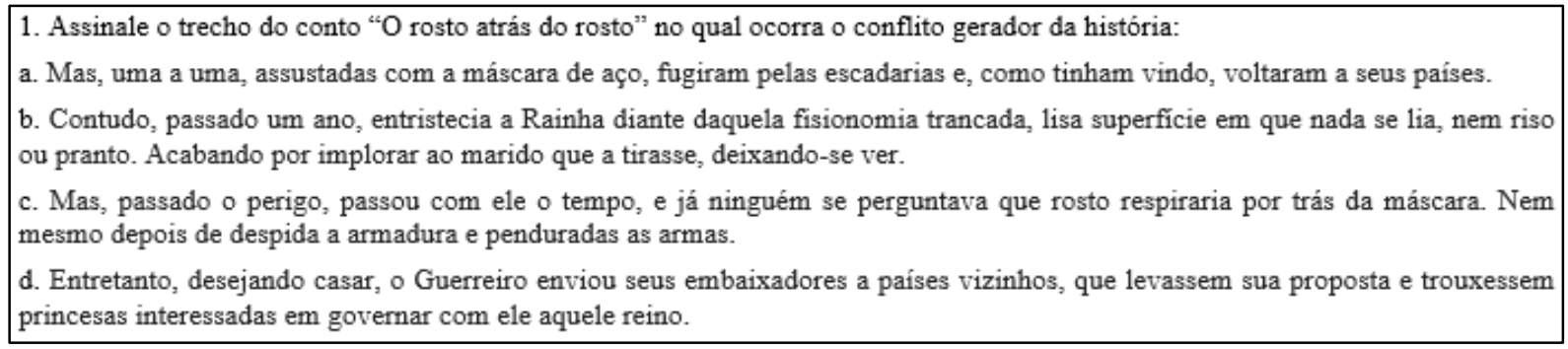

Finalizada a leitura dos dois textos, Onde os oceanos se encontram e Rosto atrás do rosto, foi iniciado o debate sobre as personagens femininas e os seus papéis na produção do conflito gerador. Foi proposto aos alunos um comparativo entre as narrativas destacando os aspectos sobrenaturais, a conexão com a realidade e os desfechos lidos.

Quadro 7. Resumo da atividade 7

\begin{tabular}{|c|c|l|}
\hline \multirow{1}{*}{ Atividade 7 } & \multicolumn{2}{|c|}{ Apresentação das conjunções adversativas e dos marcadores temporais. } \\
\cline { 2 - 3 } & Otividades & $\begin{array}{l}\text { Compreender a funcionalidade das conjunções e marcadores temporais; } \\
\text { Reconhecer a importância das conjunções e marcadores temporais no conto. }\end{array}$ \\
\cline { 2 - 3 } & $\begin{array}{l}\text { Explicação sobre as conjunções e marcadores temporais; } \\
\text { Leitura coletiva dos contos Onde os oceanos se encontram e Rosto atrás do } \\
\text { rosto, ambos de Marina Colasanti; } \\
\text { Análise das personagens femininas nos contos apresentados; } \\
\text { Identificação dos conflitos a partir dos marcadores conjuntivos e temporais. }\end{array}$ \\
\cline { 2 - 3 } & Material & $\begin{array}{l}\text { Folha com o conto impresso Onde os oceanos se encontram; } \\
\text { Folha com o conto impresso Rosto atrás do rosto. }\end{array}$ \\
\cline { 2 - 3 } & Duração & 6 horas-aula \\
\hline
\end{tabular}

A oitava atividade objetivava proporcionar aos alunos a oportunidade de aplicar os conteúdos apreendidos por meio das atividades anteriores e reconhecer o conflito gerador sem a utilização dos marcadores adversativos e temporais. Para isso, pensou-se na seleção de outro conto de Colasanti chamado de Entre a espada e a rosa ${ }^{14}$, para realizar, oralmente, uma análise das personagens femininas nos contos apresentados e avaliar os alunos com vistas a verificação da aprendizagem.

\footnotetext{
${ }^{13}$ Elaborado para esta pesquisa.

${ }^{14}$ COLASANTI, Marina. Mais de 100 histórias maravilhosas. São Paulo: Global, 2015.
} 
Como já descrito na atividade anterior, estratégias de antecipação e mediação foram, novamente, aplicadas, entregando-se, aos alunos, folhas com o conto Entre a espada e a rosa, de Marina Colasanti, nas quais havia perguntas acerca do título, questões que exploravam o papel metafórico dos vocábulos espada e rosa, e questões que tratavam do ambiente em que se passava a narrativa e dos personagens envolvidos.

Após a leitura, pôde-se debater acerca da importância da personagem Princesa e, na sequência, foi solicitado aos alunos que relessem o conto e identificassem o conflito gerador. Esse conto de Colasanti, ao contrário da maioria, não possui qualquer marcador para assinalar o desequilíbrio causado pelo conflito gerador no enredo. Os alunos deveriam se apoiar, somente, nos aspectos contextuais do conto.

Figura 8. Exemplo de questão ${ }^{15}$

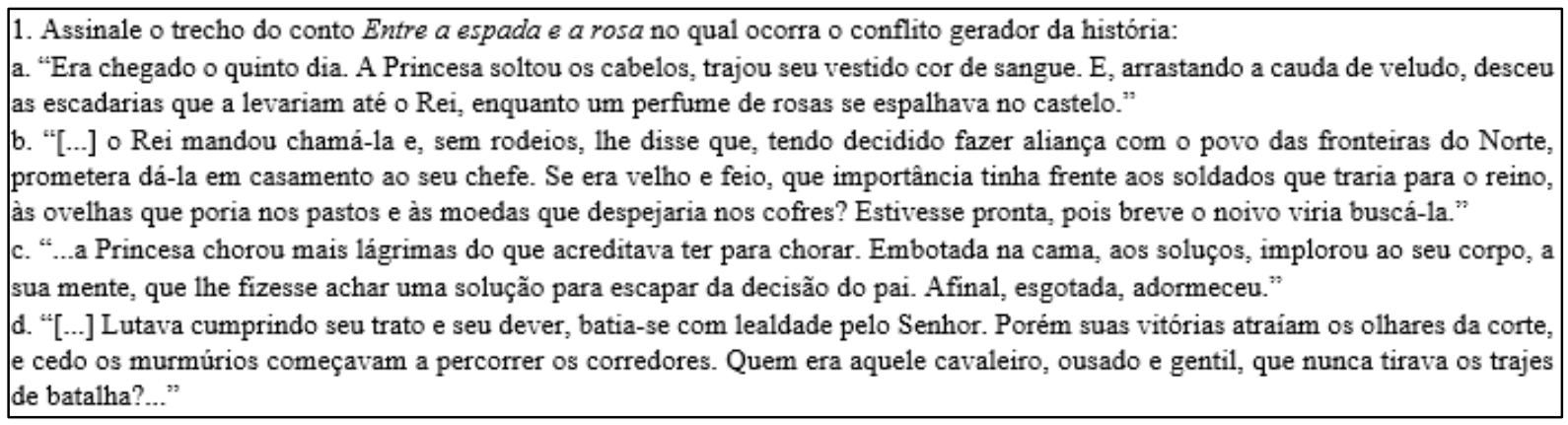

Os resultados obtidos na atividade 8 representem uma inversão positiva em comparação aos resultados coletados na atividade 1 . Os acertos aumentaram e o mismatch diminuiu. Tal resultado só possível após a aplicação de três estratégias relatadas ao longo desta seção: a definição de uma temática motivadora, a utilização de recursos concretos para a identificação do conflito e a mediação da leitura realizada pelo professor. E como bem afirma Yunes (2009):

Dentro e fora da escola, crianças e adultos, precisamos reaprender a ler, a reinventar a leitura. E o começo é perceber que não lemos palavras, lemos sequências nas quais as palavras se comunicam, se negam, se contradizem e nos surpreendem: espreitar suas relações, observar suas ambiguidades pode nos tornar mais perspicazes e sensíveis. Viver a aventura da palavra é viajar pelo tempo/espaço da humana condição. (YUNES, 2009, p. 58)

${ }^{15}$ Elaborado para esta pesquisa. 
Entende-se que a compreensão da leitura deve ser sempre motivada e mediada por um outro leitor mais experiente. Os professores podem inovar o ensino de leitura na sala de aula e, até mesmo, melhorar a relação com os alunos por meio da mediação. As habilidades devem ser trabalhadas em sala de aula sempre com planejamento e colocando o aluno no centro do processo, sendo sempre importante que haja uma preocupação com os motivos que levam o aluno ao erro.

Quadro 8. Resumo da atividade 8

\begin{tabular}{|l|l|l|}
\hline \multirow{4}{*}{ Atividade 8 } & \multicolumn{3}{|c|}{ Atividade final para o reconhecimento do conflito gerador. } \\
\cline { 2 - 3 } & Objetivo & $\begin{array}{l}\text { Aplicar os conteúdos apreendidos nas atividades anteriores; } \\
\text { Reconhecer o conflito gerador sem a utilização dos marcadores } \\
\text { adversativos e temporais. }\end{array}$ \\
\cline { 2 - 3 } & Atividades & $\begin{array}{l}\text { Leitura oral do conto Entre a espada e a rosa de Marina Colasanti; } \\
\text { Análise das personagens femininas nos contos apresentados; } \\
\text { Realização de avaliação final. }\end{array}$ \\
\cline { 2 - 3 } & Material & Folha com o conto impresso Entre a espada e a rosa. \\
\cline { 2 - 3 } & Duração & 2 horas-aula \\
\hline
\end{tabular}

\section{Considerações finais}

O problema da identificação do conflito gerador nas narrativas trabalhadas em sala de aula pelo professor é consequências da dificuldade na leitura e interpretação de textos por parte dos alunos. Esse problema já foi reconhecido por programas internacionais que visam avaliar a capacidade de leitura e interpretação de textos em estudantes do mundo todo. O Programa Internacional de Avaliação de Alunos (PISA ${ }^{16}$ ) informou que o Brasil obteve, na mais recente avaliação, 410 pontos na área de leitura, ou seja, dois a menos que o obtido na avaliação anterior. Ocupando a 55 $5^{\mathrm{a}}$ posição do ranking, o Brasil situa-se atrás de nações como Chile, Uruguai, Romênia e Tailândia nesse quesito. Segundo a referida avaliação, os alunos avaliados não conseguiram inferir informações do texto, estabelecer relações entre partes diferentes do mesmo e não foram capazes de compreender as sutilezas da linguagem.

Parte-se, então, do pressuposto de que o que pode estar contribuindo para os resultados pouco expressivos nas avaliações internacionais é o trabalho desenvolvido nas escolas do país

\footnotetext{
${ }^{16}$ INEP. Resultados do PISA 2015. Disponível em: http://portal.inep.gov.br/internacional-novo-pisaresultados, acesso em 18 de junho de 2016.
} 
que tem apresentado um modelo de ensino que não leva em conta a necessidade de utilização de estratégias cognitivas que possam ensinar o aluno a pensar.

Motivados pelas necessidades apontadas pelas avaliações citadas no parágrafo anterior, além das observações que são fruto da prática docente, percebeu-se a urgência em se buscar uma investigação que propusesse alternativas para a melhoria progressiva do ensino de língua portuguesa em sala de aula. Seguindo um viés linguístico e não puramente educacional, optou-se pela seleção de um conteúdo escolar que pudesse partir de estudos cognitivos, passasse pela decodificação por meio de estudos semânticos e fosse resolvido com a aplicação da mediação da leitura, já que esta é uma dificuldade emergente dos alunos da geração atual: a habilidade específica denominada Identificar o conflito gerador, precisamente com alunos do Ensino Fundamental.

A partir da constatação de que os mismatches semânticos ocorrem por conta de uma deficiência de leitura e de um vocabulário pouco diversificado, fruto do pouco acesso a textos escritos de qualidade e influências do ambiente conflituoso que os jovens estão inseridos, foram pensadas estratégias de mediação pedagógica que pudessem dar conta dos problemas detectados. Por este ser um fenômeno cognitivo, não se espera que ele simplesmente deixe de ocorrer, mas que haja preocupação dos educadores em não deixar que isso influencie no resultado das avaliações e que conteúdos escolares possam ser aprendidos de forma errada.

Apresentou-se uma forma adequada de evitar o fenômeno chamado de mismatch semântico. O planejamento das ações é o diferencial para o sucesso da mediação pedagógica, sendo uma prática que deve ser sempre adotada. A mediação de leitura deve ser divulgada e incorporada à cultura do ensino de língua portuguesa a fim de minimizar os diversos problemas acarretados pela má interpretação de textos. Com isso, é possível concluir que o trabalho de mediação pedagógica de leitura e reconhecimento dos processos cognitivos para construção do significado deve ser aplicado em todas as etapas da Educação Básica.

Espera-se que, com a proposta de mediação pedagógica apresentada neste artigo, os professores do ensino básico possam contar com novas formas de identificar o conflito gerador, contribuindo para a melhoria progressiva do ensino da metalinguagem em sala de aula.

\section{Referências}


ARAÚJO, Liane Castro de. Reescrevendo a escrita na escola: a prática de revisão e reescrita textual mediada por pares. Salvador, UFBA, 2004. (Mestrado em Educação), do Programa de Pós-Graduação em Educação da Universidade Federal da Bahia, 2004.

BIDERMAN, Maria Tereza de Camargo. Teoria Linguística: linguística, quantitativa e computacional. Rio de Janeiro: LTC, 2001.

BRASIL. Ministério da Educação. Plano de Desenvolvimento da Educação: SAEB. Brasília: MEC, SAEB; $\quad$ INEP, 2008. Disponível em: http://portal.mec.gov.br/dmdocuments/prova\%20brasil_matriz2.pdf, acesso em 11 de janeiro de 2017.

Ministério da Educação. Simulado Prova Brasil $8^{a}$ série $/ 9^{\circ}$ ano 2011. Brasília: MEC, SAEB, INEP, 2008. Disponível em: http://portal.mec.gov.br/prova-brasil/simulado-provabrasil-2011. Acesso em 18 de julho de 2017.

BRODBECK, Regina Célia Martins Salomão. Um monte de problemas gera uma chuva de respostas: estudo de um caso de desencontro na quantificação nominal em português. Juiz de Fora: UFJF, 2010. 149f. Tese (Doutorado em Linguística) - Faculdade de Letras, Universidade Federal de Juiz de Fora, Juiz de Fora, 2010.

CANÇADO, Marcia. Manual de Semântica: noções básicas e exercícios. São Paulo: Contexto, 2015.

COLASANTI, Marina. A moça tecelã. São Paulo: Global, 2004.

. Mais de 100 histórias maravilhosas. São Paulo: Global, 2015.

. Um espinho de marfim e outras histórias. Porto Alegre: L\&PM, 1999.

CROFT, Willian; CRUSE, Alan. Cognitive Linguistics. (Cambridge Textbooks in Linguistics). Cambridge: Cambridge University Press, 2004.

FILLMORE, Charles. Frames and the semantics of understanding. Quaderni di semantica 6: Journal Article, 1986.

1982.

Frame semantics, in: Linguistics in the morning calm. Seul: Hanshin Publishing Co.,

Scenes-and-frames semantics, Linguistic Structures Processing. In: Linguistic Structure Processing. Amsterdam: North Holland Publishing Company, 1977.

FLAVELL, John H. Metacognition and cognitive monitoring: A new area of cognitvedevelopmental inquiry. American Psychologist, EUA, V. 34, n. 10, 1979.

INSTITUTO AYRTON SENNA. Fórmula da Vitória. São Paulo: Global Editora, 2011. 
FRANCIS, Elaine J.; MICHAELIS, Laura. Mismatch: form function in congruity and the architecture of grammar. Califórnia: CSLI, 2002.

GANCHO, Candida Vilares. Como analisar narrativas. São Paulo: Editora Ática, 2002.

GARCEZ, Lucília Helena do Carmo. Técnicas de redação: o que é preciso para saber escrever bem. São Paulo: Martins Fontes, 2001.

GARCIA, Othon Moacyr. Comunicação em prosa moderna: aprenda a escrever, aprendendo a pensar. 27. ed. Rio de Janeiro: Editora FGV, 2010.

KLEIMAN, Angela. Oficina de leitura: teoria e prática. Campinas: Pontes, 2000.

Texto e leitor: aspectos cognitivos da leitura. São Paulo: Pontes, 1989.

MACEDO, Walmírio. Gramática da Língua Portuguesa. Rio de Janeiro: Presença Edições, 1991.

MOISÉS, Massaud. A criação literária: prosa 1. 20. ed. São Paulo: Cultrix, 2006.

MORAIS, Artur Gomes. A norma ortográfica do português: o que é? para que serve? como está organizada? In: SILVA, A.; MORAIS, A. G.; MELO, K. L. R. (Orgs.) Ortografia na sala de aula. Belo Horizonte: Autêntica, 2007

MORGANTI, Francesca. What Intersubjectivity Affords: Paving the Way for a Dialogue between Cognitive Science, Social Cognition and Neuroscience. In: Enacting Intersubjectivity: A Cognitive and Social Perspective on the Study of Interactions. F. Morganti, A. Carassa, G. Riva (Eds.) Amsterdam, IOS Press, 2008.

SOLÉ, Isabel. Estratégias de Leitura. Porto Alegre: Artmed, 1998.

TAMBA, Irene. A semântica. São Paulo: Parábola Editorial, 2006.

TOMASELLO, Michael. Origens culturais da aquisição do conhecimento humano. Harvard: University Press. 2003.

YUNES, Eliana. Tecendo um leitor: uma rede de fios cruzados. Curitiba: Aymará, 2009.

ZLATEV, Jordan, RACINE, Timothy, SINHA, Chris e ITKONEN, Esa. (Eds.) The shared mind: Perspectives on intersubjectivity. Amsterdam: John Benjamins, 2008. 